\title{
Malingering and PTSD: Detecting malingering and war related PTSD by Miller Forensic Assessment of Symptoms Test (M-FAST)
}

\author{
Khodabakhsh Ahmadi ${ }^{*}$, Zeynab Lashani ${ }^{1}$, Mohammad Hassan Afzali', S Abbas Tavalaie ${ }^{2}$ and Jafar Mirzaee ${ }^{3}$
}

\begin{abstract}
Background: Malingering is prevalent in PTSD, especially in delayed-onset PTSD. Despite the attempts to detect it, indicators, tools and methods to accurately detect malingering need extensive scientific and clinical research. Therefore, this study was designed to validate a tool that can detect malingering of war-related PTSD by Miller Forensic Assessment of Symptoms Test (M-FAST).

Methods: In this blind clinical diagnosis study, one hundred and twenty veterans referred to War Related PTSD Diagnosis Committee in Iran in 2011 were enrolled. In the first step, the clients received Psychiatry diagnosis and were divided into two groups based on the DSM-IV-TR, and in the second step, the participants completed M-FAST.

Results: The $t$-test score within two groups by M-FAST Scale showed a significant difference $(t=14.058, P<0.0001)$, and $92 \%$ of malingering war-related PTSD participants scored more than 6 and \%87 of PTSD group scored less than 6 in M-FAST Scale.

Conclusions: M-FAST showed a significant difference between war-related PTSD and malingering participants. The $\geq 6$ score cutoff was suggested by M-FAST to detect malingering of war-related PTSD.

Keywords: Post-traumatic stress disorder (PTSD), Miller forensic assessment of symptoms test (M-Fast), Malingering, Combat disorder
\end{abstract}

\section{Background}

Post-traumatic stress disorder (PTSD) is one of the most prevalent psychiatric disorders in veterans [1]. PTSD was reported to be more frequent in Iranian warfare victims in comparison with other disabled veterans [1,2]. Malingering sometimes occurs among patients who seek treatment for PTSD as a result of war-related trauma experiences [3]. Pseudo-posttraumatic stress disorder refers to cases in which a patient's presentation is a simulation of the actual clinical syndrome. Malingering of PTSD has been neglected by many clinicians and researchers who often rely on the assumption that a patient's reported symptoms can be accepted as valid [4]. PTSD is particularly vulnerable to malingering because the diagnostic process heavily relies on the patient's subjective report of his/her symptoms [5] and

\footnotetext{
*Correspondence: kh_ahmady@yahoo.com

${ }^{1}$ Behavioral Sciences Research Center, Baqiyatallah University of Medical Sciences, P.O. Box: 19395-5487, Tehran, Iran

Full list of author information is available at the end of the article
}

different interpretations on traumatic experiences and the severity of an individual's emotional consequence make PTSD easy to malinger [6]. In addition, symptom overlap (insomnia, numbing, startle, anxiety, depression, fatigue, loss of affinity with others, etc.) makes the diagnosis even more difficult to determine [3,7]. In such studies, PTSD malingering is estimated to occur in at least $20 \%$ of compensation-seeking combat veterans [8]. Moreover, it is important for the assessor psychiatrist to understand his/her role in evaluating a patient claiming PTSD [5]. In a treatment or consultation setting, most therapists take their patients' reported symptoms at face value since it is assumed that it is in the patients' best interest to be honest with their doctors for the best treatment [5]. However, psychological testing can be useful in alerting the interviewer to possible malingering and to support the decision on malingering [5,9].

Psychological tests created and used to diagnose PTSD cannot detect malingering [10]. Lange et al. [9] showed that

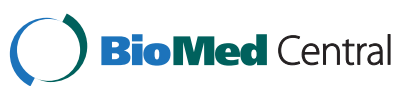


malingered PTSD cases had significantly higher scores in the majority of MMPI-2 and PAI validity indicators. Nelson et al. [11] suggested that among many MMPI-2 validity scales examined (e.g., L, F, K, Fb, Fp, and FBS), FBS yielded the largest effect size for differences between a group of participants with secondary gain and a group with no secondary gain. Another screening instrument for malingering of mental illnesses has recently been developed by Miller et al. [12] as an abbreviated version of the Structured Interview of Reported Symptoms (SIRS), the M-FAST. The M-FAST is a brief, structured interview that assesses malingering of psychotic symptoms based on the overall response style. Initial studies have found that the M-FAST is successful in detecting malingering in known group comparisons and it is moderately a useful assessment in classifying individuals as either honest responders or malingerers [13]. The outpatients' disability claimants that were suspected of malingering had significantly higher total M-FAST scores than honest responders [12]. Strunk et al. [14] showed that M-FAST correctly identified $78 \%$ of coached malingerers. Guriel et al. [14] showed that M-FAST and Trauma Symptom Inventory (TSI) identified 90\% cases of malingering of PTSD and Guy et al. [15] showed that malingers got more score than clinical participants in M-FAST (with Schizophrenia, major depression, bipolar and acute traumatic stress disorders). Furthermore, Jackson and colleagues [16] indicated that the $\geq 6$ score in forensic assessment is a cutoff point for detected malingers in prisons. Although detecting war-related malingering is really important to clinicians, there are few published methods specifically designed for detecting exaggeration of psychological symptoms [7,17] and the structured inventory of malingering symptomatology across the world $[7,18]$ and especially after Iraq-Iran war, in Iran. Therefore, this study was designed to detect malingering from war-related PTSD by Miller Forensic Assessment of Symptoms Test (M-FAST).

\section{Methods}

In this blind clinical diagnosis study, the participants were 120 veterans referred to War Related PTSD Diagnosis Committee in Baqiyatallah and Sadr hospitals, in Tehran, Iran in 2011. All the participants were diagnosed as having PTSD of direct combat conditions, with none of them having PTSD of other related events (captivity, accidents, etc.). The addicted clients and the ones with organic illnesses were excluded from the study. This research had two steps. At the first step, the clients were visited by psychiatrists and evaluated for PTSD and finally were divided into two groups: some of them were diagnosed as PTSD, and for the second group, a PTSD diagnosis was ruled out. In this step, the diagnosis criteria were based on the Diagnostic and Statistical Manual of
Mental Disorders (DSM-IV- TR, 2000). So, another research team performed the second step without knowing the results of the first team diagnosis. In this step, participants completed the Miller Forensic Assessment of Symptoms Test (M-FAST) for detecting malingering. In this study, we administered Persian version of M-FAST with acceptable internal consistency $(\alpha$-Chronbach's $=0.86$ ). Finally the original researchers analyzed and compared the data of two research teams. The proposal of this research was approved by ethics committee in Baqiyatallah University of Medical Sciences. So, all of the participants voluntarily completed the consent form before entering the study. There was no coercion upon the study subjects for participation.

The brief structured interview of M-FAST includes 25 items and is designed to detect malingering by assessing individuals' general response style. The M-FAST contains seven subscale scores and an overall total score. The seven subscales are based on strategies used to detect malingerers, reported versus observed symptoms, extreme symptoms, rare combinations, unusual hallucinations, unusual symptom course, negative image and suggestibility (Miller et al. 2000 \& Miller, 2001). The re-test reliability for the total score over a one week interval was 0.92 among psychiatric inpatients, and alpha for the total score was 0.93 among inpatients and 0.92 in non-clinical participants (Miller, 2001). Miller (2001) recommends a cutoff score of 6 or greater to predict malingering, which showed a sensitivity of 0.93 and a specificity of 0.83 in a clinical population in an initial validity study.

The data were analyzed using descriptive methods, and the cutoff points were calculated by sensitivity, specificity, hit rate, and $t$-test. In this study, the diagnosis, response measurements and research on malingering war-related PTSD were conducted by three separate collaborating groups.

\section{Results}

Baseline characteristics of the participants are demonstrated in Table 1. All participants were men and

\begin{tabular}{|c|c|c|}
\hline & PTSD $(n=76)$ & Malingering $(n=44)$ \\
\hline Age (years) & $47.18 \pm 6.10$ & $44.30 \pm 4.80$ \\
\hline \multicolumn{3}{|l|}{ Marital status, n (\%) } \\
\hline married & $76(100)$ & $44(100)$ \\
\hline \multicolumn{3}{|l|}{ Level of education, n (\%) } \\
\hline$<$ high school & $19(25.0)$ & $10(22.7)$ \\
\hline high school & $40(52.6)$ & $25(56.8)$ \\
\hline Bachelor's & $16(21.1)$ & $8(18.2)$ \\
\hline Master's and higher & $1(1.3)$ & $1(2.3)$ \\
\hline
\end{tabular}


Table 2 The mean, standard division, error's standard division and $t$-test of two groups

\begin{tabular}{|c|c|c|c|c|c|c|c|c|}
\hline Group & & mean & Standard deviation & Minimum score & Maximum score & t-statistic & df & $P$ value \\
\hline \multirow[t]{2}{*}{ M-FAST } & Malingered & 8.28 & 2.12 & 2 & 13 & 14.05 & 116.31 & 0.0001 \\
\hline & War PTSD & 3.13 & 1.88 & 1 & 7 & & & \\
\hline
\end{tabular}

Abbreviation: M-FAST, Miller-Forensic Assessment of Symptoms Test; $d f$ : degree of freedom.

married with mean age of 45.6 in range of 445.93 to 45.63 years. The majority of participants were high school graduates.

Mean, standard division and $t$-test for two groups (War-related PTSD \& malingering for war-related PTSD) in M-FAST are shown in Table 2. According to the $t$-test score, $(\mathrm{t}=14.058, \mathrm{df}=116.31, \mathrm{P}>0.000)$ M-FAST shows a significant difference between war-related PTSD group and malingering group (Table 2). According to the M-FAST results (PTSD $=3.13$ \& Malingering $=8.28$ ), PTSD patients had scored less than malingering participants. The comprehension of frequencies in two groups and predictive power values for M-FAST validity indicators are used to detect malingered PTSD and war-related PTSD (Table 2).

According to Table 3, based on specificities (87) and sensitivities (92), the cutoff point 6 for M-FAST scales was the point of malingering group to war-related PTSD disorder. Also, 92\% of malingers to war-related PTSD got more than 6 scores and \%87 of PTSD group got less than 6 scores in M-FAST scale (Table 3). The results are shown in Figure 1.

Table 3 Operating characteristics of M-FAST scale for two groups

\begin{tabular}{lllllll}
\hline & & $\begin{array}{l}\text { Malingering } \\
\text { group }\end{array}$ & $\begin{array}{l}\text { War PTSD } \\
\text { group }\end{array}$ & Specify & Sensitivity & HR \\
\hline M-FAST & 1 & 0 & 16 & 100 & 27 & 37 \\
& 2 & 1 & 12 & 100 & 47 & 27 \\
& 3 & 2 & 7 & 98 & 58 & 21 \\
& 4 & 0 & 9 & 95 & 73 & 16 \\
& 5 & 3 & 8 & 95 & 87 & 9 \\
& $6^{\text {a }}$ & $\frac{3^{\mathrm{a}}}{9}$ & $\frac{5^{\mathrm{a}}}{3}$ & $\frac{87^{\mathrm{a}}}{85}$ & $\underline{92^{\mathrm{a}}}$ & $\frac{8^{\mathrm{a}}}{100}$ \\
& 7 & 9 & 3 & 85 & 100 & 8 \\
& 8 & 11 & 0 & 70 & 100 & 15 \\
& 9 & 15 & 0 & 52 & 100 & 24 \\
& 10 & 9 & 0 & 27 & 100 & 37 \\
& 11 & 5 & 0 & 12 & 100 & 44 \\
& 12 & 1 & 0 & 3 & 100 & 48 \\
& 13 & 1 & 0 & 2 & 100 & 49 \\
Total & 60 & 60 & & & \\
\hline
\end{tabular}

${ }^{\mathrm{a}}$ : cutoff point; sensitivity: percentage of malingering and war-related PTSD groups correctly classified at cutting score; specificity: percentage of malingering and war-related PTSD groups correctly classified at cutting score: $H R$, overall hit rate: percentage of all groups correctly classified.

\section{Note}

Sensitivity is the true positive (Hit) rate for the test (number of people with positive test result divided by summation of true positives and false negatives). Specificity is the true negative rate (number of people with true negatives and false positives). Sensitivity and specificity are directly dependent on the classification scheme (cut off) employed with a given diagnostic technique and are independent of base rates (Hennekens \& Buring, 1987). For clinical diagnosis, sensitivity and specificity must be "translated" into positive predictive power (PPP) and negative predictive power (NPP) which are dependent on base rates (Gouvier, Hayes \& Smiroldo, 1998).

\section{Discussion}

In the present study, we found that there is a significant difference between the two groups regarding diagnosis of PTSD. According to the $t$-test score $(\mathrm{t}=14.058, \mathrm{df}=116.31$, $\mathrm{P}<0.001)$ within the two groups by M-FAST scale, there was a significant difference between war-related PTSD and the malingering group. Based on specificities (87) and sensitivities (92), the cutoff point of 6 in M-FAST scales

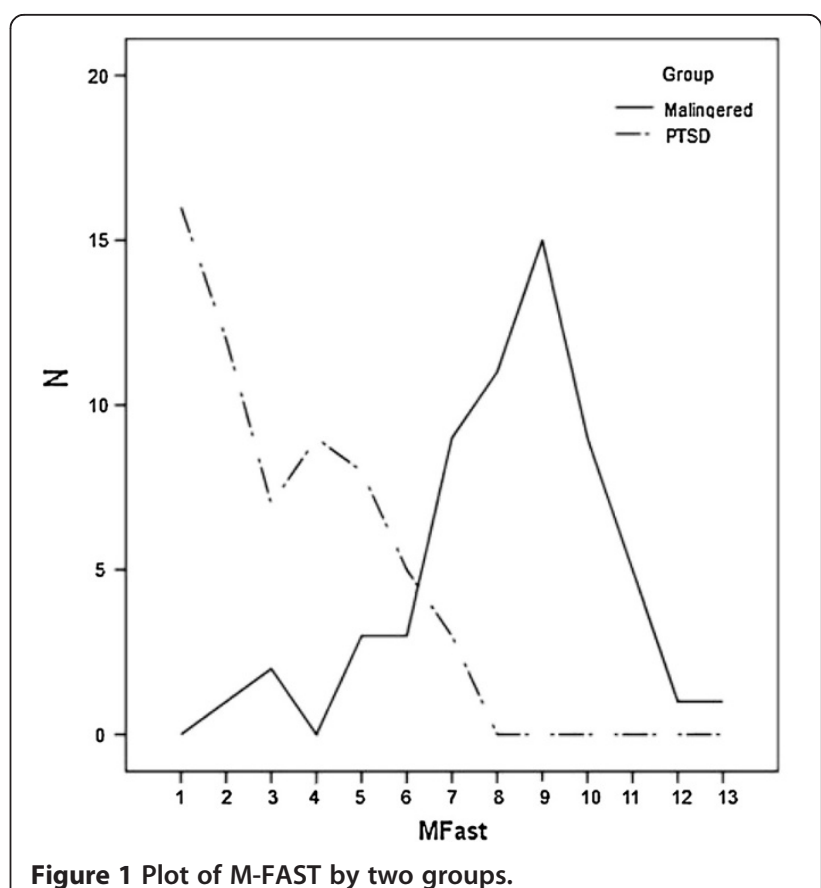


was the point of malingering group to war-related PTSD disorder. Also, 92\% of malingering of war-related PTSD people scored more than 6 and \%87 of PTSD group scored less than 6 in M-FAST scale. Whereas the prevalence rates or the percentage of individuals with PTSD are obvious in a lifetime after wars, it seems necessary to evaluate veterans for PTSD every year. Accordingly, the M-Fast can be suitable for detecting the malingering of PTSD.

These finding are the same as those in previous studies, for example: Strunk et al. [14] showed M-Fast correctly identified $78 \%$ of coached malingerers. Guriel et al. [19] showed M-FAST and TSI detected $90 \%$ of malingering to the PTSD and Guy et al. [15] suggested that malingering people scored higher in the M-FAST than clinical participants (with Schizophrenia, major depression, bipolar and acute traumatic stress disorders). Jackson et al. [16] indicated that the $\geq 6$ score is a cutoff point for detecting malingering people in forensic assessment in prisons.

So, our study is in accordance with the previous ones, and shows that M-FAST scales can be effectively used in Iranian veterans with PTSD symptoms. This probably proves that cultural aspects play no major role in the validity of M-FAST scale to detect malingering in veterans. However, one should consider that despite the high detection rate of malingering achieved by M-FAST, it is not $100 \%$ diagnostic, and still a good proportion of undetected cases exist. So, interpretation of findings derived from M-FAST should be undertaken cautiously.

This study has some powerful points as well as limitations. As a strength point for this study, we can note the relatively large number of the study subjects, and the data from Iranian veterans of Iraq-Iran war. Moreover, we used a blind assessment to address the PTSD in the current study. We also used standardized measures in our approach. On the other hand, we can call the long time after the war as a weak point for our study, while this might be able to adversely affect the validity of our study results.

\section{Conclusion}

The present results suggest M-FAST for detecting malingering of war related PTSD cases among Iranian veterans because M-FAST is a brief scale with high rate of validity in this patient population. Of course, we need further studies for investigating M-FAST ability to detect malingering for other disorders.

\section{Competing interests}

The authors declare that they have no competing interest. The authors specify that, we haven't any financial competing interests (political, personal, religious, ideological, academic, intellectual, commercial or any other) to declare in relation to this manuscript

\section{Authors' contributions}

KA conceived the study, participated in its design, coordination, and interpretation of the results. MHA was involved in recruiting patients and collection of data. ZL performed statistical analyses. JM contributed to patient recruitment and also prepared early draft of the manuscript. SAT participated in visiting patients and diagnosed PTSD. All authors read and approved the final manuscript.

\section{Acknowledgment}

The authors would like to thank war veterans and managers in Baqiyatallah and Sadr hospitals for their assistance.

\section{Author details}

${ }^{1}$ Behavioral Sciences Research Center, Baqiyatallah University of Medical Sciences, P.O. Box: 19395-5487, Tehran, Iran. ${ }^{2}$ Department of Psychiatry department, Baqiyatallah Hospital, Tehran, Iran. ${ }^{3}$ Sadr Hospital, Tehran, Iran.

Received: 28 February 2012 Accepted: 15 May 2013

Published: 29 May 2013

\section{References}

1. Ahmadi K, Reshadatjoo M, Karami GR, Sepehrvand N, Ahmadi P, BazarganHejazi S: Evaluation of secondary post-traumatic stress disorder symptoms in the spouses of chemical warfare victims 20 years after the Iran-Iraq war. Psychiatrist 2011, 35:168-175.

2. Ahmadi K, Reshadatjoo M, Karami G, Sepehrvand N, Ahmadi P: Vicarious PTSD in Sardasht chemical warfare victims' offspring. Procedia Social Behav Sci 2010, 5:170-173.

3. Taylor S, Frueh BC, Asmundson GJG: Detection and management of malingering in people presenting for treatment of posttraumatic stress disorder: methods, obstacles, and recommendations. J Anxiety Disorders 2007, 21:22-41.

4. Rosen GM, Taylor S: Pseudo-Ptsd. J Anxiety Disorders 2007, 21:201-210.

5. Brady KT, Killeen TK, Brewerton T, Lucerini S: Comorbidity of psychiatric disorders and posttraumatic stress disorder. J Clin Psychiatry 2000, 61(Suppl 7):22-32. PMID: 10795606 [PubMed - indexed for MEDLINE.

6. Sparr LF: Mental defenses and posttraumatic stress disorder: assessment of criminal intent. J Trauma Stress 1996, 9:405-425.

7. Hall RCW: Malingering of PTSD: forensic and diagnostic considerations, characteristics of malingerers and clinical presentations. Gen hospital psychiatry 2006, 28:525-535.

8. Frueh BC, Hamner MB, Cahill SP, Gold PB, Hamlin KL: Apparent symptom overreporting in combat veterans evaluated for PTSD. Clin Psychol Rev 2000, 20:853-885.

9. Lange RT, Sullivan KA, Scott C: Comparison of MMPI-2 and PAI validity indicators to detect feigned depression and PTSD symptom reporting. Psychiatry res 2010, 176:229-235.

10. Resnick PJ, West S, Payne JW: Malingering of posttraumatic disorders. Clin assess malingering deception 1997, 2:130-152.

11. Nelson NW, Sweet JJ, Heilbronner RL: Examination of the new MMPI-2 response bias scale (gervais): relationship with MMPI-2 validity scales. J Clin Exp Neuropsychol 2007, 29:67-72.

12. Slick DJ, Tan JE, Strauss EH, Hultsch DF: Detecting malingering: a survey of experts' practices. Arch Clin Neuropsychol 2004, 19:465-473.

13. Strauss E, Slick DJ, Levy-Bencheton J, Hunter M, MacDonald SWS, Hultsch DF: Intraindividual variability as an indicator of malingering in head injury. Arch Clin Neuropsychol 2002, 17:423-444.

14. Strunk JM: Detecting malingered posttraumatic stress disorder using the Morel Emotional Numbing Test-Revised (MENT-R) and the Miller Forensic Assessment of Symptoms Test (M-FAST). Virginia, USA: West Virginia University; 2005.

15. Guy LS, Kwartner PP, Miller HA: Investigating the M-FAST: psychometric properties and utility to detect diagnostic specific malingering. Behav Sci Law 2006, 24:687-702

16. Jackson RL, Rogers R, Sewell KW: Forensic applications of the Miller Forensic Assessment of Symptoms Test (MFAST): screening for feigned disorders in competency to stand trial evaluations. Law Hum Behav 2005, 29:199-210.

17. Silverton L, Gruber C: Malingering Probability Scale (MPS). Los Angeles, CA: Western Psychological Services; 1998. 
18. Smith GP, Burger GK: Detection of malingering: validation of the Structured Inventory of Malingered Symptomatology (SIMS). J Am Acad Psychiatry Law 1997, 25(2):183-189. PMID: 9213290 [PubMed - indexed for MEDLINE.

19. Guriel J, Yañez T, Fremouw W, Shreve-Neiger A, Ware L, Filcheck H, Farr C: Impact of coaching on Malingered Posttraumatic Stress Symptoms on the M-FAST and the TSI. J Forensic Psyc Pract 2004, 4:37-56.

doi:10.1186/1471-244X-13-154

Cite this article as: Ahmadi et al:: Malingering and PTSD: Detecting malingering and war related PTSD by Miller Forensic Assessment of Symptoms Test (M-FAST). BMC Psychiatry 2013 13:154.

\section{Submit your next manuscript to BioMed Central and take full advantage of:}

- Convenient online submission

- Thorough peer review

- No space constraints or color figure charges

- Immediate publication on acceptance

- Inclusion in PubMed, CAS, Scopus and Google Scholar

- Research which is freely available for redistribution 